\title{
The effects of omega-3 fatty acids and vitamin E co-supplementation on gene expression of lipoprotein(a) and oxidized low-density lipoprotein, lipid profiles and biomarkers of oxidative stress in patients with polycystic ovary syndrome
}

\author{
Elham Rahmani ${ }^{\text {a }}$, Mansooreh Samimi ${ }^{\text {b }}$, Faraneh Afshar Ebrahimi ${ }^{\text {b }}$, \\ Fatemeh Foroozanfard $^{\mathrm{b}}$, Shahnaz Ahmadi ${ }^{\mathrm{a}, \mathrm{c}}$, Maryam Rahimi ${ }^{\mathrm{c}}$, Mehri Jamilian ${ }^{\mathrm{d}}$, \\ Esmat Aghadavod ${ }^{\mathrm{e}}$, Fereshteh Bahmani ${ }^{\mathrm{e}}$, Mohsen Taghizadeh ${ }^{\mathrm{e}}$, \\ Mohammad Reza Memarzadeh ${ }^{\mathrm{f}}$, Zatollah Asemi ${ }^{\mathrm{e}}{ }^{*}$ \\ a Department of Gynecology and Obstetrics, School of Medicine, Bushehr University of Medical Sciences, Bushehr, Iran \\ b Department of Gynecology and Obstetrics, School of Medicine, Kashan University of Medical Sciences, Kashan, Iran \\ ${ }^{c}$ Department of Gynecology and Obstetrics, School of Medicine, Iran University of Medical Sciences, Tehran, Iran \\ d Endocrinology and Metabolism Research Center, Department of Gynecology and Obstetrics, School of Medicine, Arak University of Medical Sciences, Arak, \\ Iran \\ ${ }^{\mathrm{e}}$ Research Center for Biochemistry and Nutrition in Metabolic Diseases, Kashan University of Medical Sciences, Kashan, Iran \\ ${ }^{\mathrm{f}}$ Barij Medicinal Plants Research Center, Kashan, Iran
}

\section{A R T I C L E I N F O}

\section{Article history:}

Received 8 July 2016

Received in revised form

15 August 2016

Accepted 8 September 2016

Available online 9 September 2016

\section{Keywords:}

Omega fatty acids and vitamin E

Gene expression

Lipid profiles

Oxidative stress

Polycystic ovary syndrome

\begin{abstract}
A B S T R A C T
This study was conducted to determine the effects of omega-3 fatty acids and vitamin E cosupplementation on gene expression of lipoprotein(a) (Lp[a]) and oxidized low-density lipoprotein (Ox-LDL), lipid profiles and biomarkers of oxidative stress in women with polycystic ovary syndrome (PCOS). This randomized double-blind, placebo-controlled trial was done on 68 women diagnosed with PCOS according to the Rotterdam criteria aged $18-40$ years old. Participants were randomly assigned into two groups to receive either $1000 \mathrm{mg}$ omega-3 fatty acids from flaxseed oil containing $400 \mathrm{mg} \alpha-$ Linolenic acid plus $400 \mathrm{IU}$ vitamin E supplements $(n=34)$ or placebo $(n=34)$ for 12 weeks. $\operatorname{Lp}(\mathrm{a})$ and Ox-LDL mRNA levels were quantified in peripheral blood mononuclear cells of PCOS women with RT-PCR method. Lipid profiles and biomarkers of oxidative stress were quantified at the beginning of the study and after 12-week intervention. Quantitative results of RT-PCR demonstrated that compared with the placebo, omega-3 fatty acids and vitamin E co-supplementation downregulated expressed levels of Lp(a) mRNA $(P<0.001)$ and Ox-LDL mRNA $(P<0.001)$ in peripheral blood mononuclear cells of women with PCOS. In addition, compared to the placebo group, omega-3 fatty acids and vitamin E cosupplementation resulted in a significant decrease in serum triglycerides $(-22.1 \pm 22.3$ vs. $+7.7 \pm 23.6 \mathrm{mg} / \mathrm{dL}, \mathrm{P}<0.001)$, VLDL- $(-4.4 \pm 4.5 \mathrm{vs} .+1.5 \pm 4.7 \mathrm{mg} / \mathrm{dL}, \mathrm{P}<0.001)$, total $-(-20.3 \pm 16.6$ vs. $+12.2 \pm 26.1 \mathrm{mg} / \mathrm{dL}, \mathrm{P}<0.001)$, LDL- $(-16.7 \pm 15.3$ vs. $+11.9 \pm 26.1 \mathrm{mg} / \mathrm{dL}, \mathrm{P}<0.001)$ and total-/HDLcholesterol $(-0.5 \pm 0.6$ vs. $+0.4 \pm 0.8, \mathrm{P}<0.001)$. There were a significant increase in plasma total antioxidant capacity $(+89.4 \pm 108.9$ vs. $+5.9 \pm 116.2 \mathrm{mmol} / \mathrm{L}, \mathrm{P}=0.003)$ and a significant decrease in malondialdehyde levels $(-0.3 \pm 0.4$ vs. $-0.008 \pm 0.6 \mu \mathrm{mol} / \mathrm{L}, \mathrm{P}=0.01)$ by combined omega-3 fatty acids and vitamin $\mathrm{E}$ intake compared with the placebo group. Overall, omega-3 fatty acids and vitamin E cosupplementation for 12 weeks in PCOS women significantly improved gene expression of Lp(a) and OxLDL, lipid profiles and biomarkers of oxidative stress.
\end{abstract}

() 2016 Elsevier Ireland Ltd. All rights reserved.

\footnotetext{
* Corresponding author.

E-mail address: asemi_r@yahoo.com (Z. Asemi).
}

\section{Introduction}

Polycystic ovary syndrome (PCOS) is a common metabolic and 
reproductive disorder that its prevalence ranges from 6 to $20 \%$ depending on the criteria used (Conway et al., 2014). Dislipidemia especially decreased HDL-cholesterol and increased triglyceride concentrations are certainly the most prevalent and persistent among cardiovascular risk factors in women with PCOS (Macut et al., 2013). According to the National Cholesterol Education Program guidelines, about $70 \%$ of women with PCOS have borderline or high lipid concentrations (Legro et al., 2001). In addition, few studies have reported that oxidized low-density lipoprotein (OxLDL) levels as a marker of altered lipid metabolism were significantly higher in untreated PCOS patients than controls (Macut et al., 2006; Carlioglu et al., 2014). Elevated levels of Ox-LDL are associated with the initiation and progression of atherosclerosis (Ehara et al., 2001). PCOS is also associated with oxidative stress in which increased production of free radicals and reactive oxygen species (ROS) are followed by decreased total antioxidant levels (Gonzalez et al., 2006). Oxidative stress may play a role in the dysregulation of the theca-interstitial compartment and the development of cardiovascular disease (Duleba et al., 2004; Youn et al., 2014).

The tendency towards increasing the extent of plaque formation in the third decade of life in PCOS patients suggests that risk factor modification in the population should be initiated almost in the second decade of life (Macut et al., 2013). Recently, few studies reported that omega-3 fatty acids and vitamin E administration can be associated with improved endocrine and metabolic characteristics in women with PCOS (Liepa et al., 2008; Mohammadi et al., 2012). In a study (Mohammadi et al., 2012), was observed that $4 \mathrm{~g} /$ day omega-3 fatty acids intake for 8 weeks decreased the risk for cardiovascular disease through the reduction in some lipids ratio among PCOS patients. In addition, the beneficial effects of omega-3 fatty acids and vitamin E co-supplementation on serum enzymatic antioxidants were previously reported among patients with type 2 diabetes mellitus (T2DM) (Sarbolouki et al., 2010). However, no significant effect in biomarkers of oxidative stress was observed following supplementation with omega-3 fatty acids among healthy young adults for 4 weeks (Cunnane et al., 1995) and vitamin E among hemodialysis patients (Ahmadi et al., 2013).

Co-supplementation of omega-3 fatty acids and vitamin E may work better than a single supplementation alone. In addition, omega-3 fatty acids and vitamin E co-supplementation might have a strong synergistic effect on lipid profiles and biomarkers of oxidative stress. Our previous study have shown that omega-3 fatty acids and vitamin E co-supplementation for 6 weeks among patients with gestational diabetes (GDM) had the beneficial effects on lipid profiles (Taghizadeh et al., 2016). Furthermore, joint omega-3 fatty acids and vitamin E administration might have a strong synergistic effect on adiponectin levels and peroxisome proliferatoractivated receptor gamma (PPAR $\gamma$ ) (Ramezani et al., 2015). PPAR$\gamma$ regulates expressed levels of several genes encoding proteins involved in adipocyte differentiation, fatty acid storage and glucose metabolism (Grindflek et al., 2000). Reduced expression of PPAR $\gamma$ causes insulin resistance (Kursawe et al., 2010), which in turn is associated with the pathogenesis of dyslipidemia in women with PCOS (El-Mazny et al., 2010). The aim of the current study was to evaluate the effects of omega-3 fatty acids and vitamin E cosupplementation on gene expression of lipoprotein(a) (Lp[a]) and Ox-LDL, lipid profiles and biomarkers of oxidative stress in these patients.

\section{Materials and methods}

\subsection{Participants}

In the current study, 68 patients with PCOS aged 18-40 years old referred to the Research and Clinical Center for Infertility and the Naghavi Clinic in Kashan, Iran, between December 2015 and February 2016 were included. Diagnosis of PCOS was done according to the Rotterdam criteria (2004): those with the two of the following criteria were considered as having PCOS: 1) oligo- and/or anovulation (defined as delayed menses $>35$ days or $<8$ spontaneous hemorrhagic episodes/year), 2) clinical [hirsutism using modified Ferriman-Gallwey (mFG) score of $\geq 8$ ] (2004) and/or biochemical signs of hyperandrogenism (Huang et al., 2010) and 3) polycystic ovaries (12 or more follicles in each ovary measuring 2-9 $\mathrm{mm}$ in diameter, and/or increased ovarian volume $>10 \mathrm{ml}^{3}$ ) (Rotterdam criteria, 2004). Study exclusion criteria included: pregnancy, using oral contraceptive pills (OCP), elevated levels of prolactin, thyroid disorder, endocrine diseases including diabetes or impaired glucose tolerance and gastrointestinal problems.

\subsection{Ethics statements}

The current study was conducted in accordance with the Declaration of Helsinki and informed consent was obtained from all participants. The research was approved by the ethics committee of Kashan University of Medical Sciences (KUMS) and was recorded in the Iranian website for registration of clinical trials (http://www. irct.ir:IRCT201601085623N67).

\subsection{Study design}

At the onset of the study, all individuals were matched according to age, phenotypes A (14 patients in each group) and D (20 patients in each group) of PCOS, and body mass index (BMI) at the study baseline. Phenotypes A and D were defined as oliganovulation + hyperandrogenism + polycystic ovary morphology and olig-anovulation + polycystic ovary morphology, respectively (Jamil et al., 2015). The present study was a prospective randomized double-blind placebo-controlled clinical trial. Participants were then randomly divided into two groups to receive either omega-3 fatty acids plus vitamin E supplements $(\mathrm{n}=34)$ or placebo $(n=34)$ for 12 weeks. All participants were taking metformin tablet at the initial dose of $500 \mathrm{mg}$, which was increased in a stepwise manner during the first 3 weeks to a total of $1500 \mathrm{mg} /$ day (Weerakiet et al., 2004). Participants were requested not to change their ordinary physical activity and not to take any nutritional supplements during the 12 -week trial. All participants completed 3-day food records and three physical activity records at weeks 0,3 , 6, 9 and 12 of the intervention. Daily macro- and micro-nutrient dietary intakes were analyzed by nutritionist IV software (First Databank, San Bruno, CA). In the current study, physical activity was described as metabolic equivalents (METs) in hours per day. To determine the METs for each patient, we multiplied the times (in hour per day) reported for each physical activity by its related METs coefficient by standard tables (Ainsworth et al., 2000).

\subsection{Intervention}

In the treatment group, persons received $1000 \mathrm{mg}$ omega-3 fatty acids from flaxseed oil containing $400 \mathrm{mg} \alpha$-Linolenic acid plus 400 IU vitamin E supplements for 12 weeks. Supplements and placebos capsules were similar in shape and size and manufactured by Barij Essence (Kashan, Iran).

\subsection{Treatment adherence}

Every four weeks, persons were given enough supplements to last until 3 days after their next scheduled visit and were instructed to return all the unused supplements at each visit. Participants 
were scheduled for the follow-up visits every 2 weeks for an intermediate evaluation and an ulcer debridement. To evaluate the compliance the remaining supplements were counted and subtracted from the amount of supplements provided to the participants. To increase compliance, all patients received short messages on their cell phones every day to remind them about taking the capsules.

\subsection{Assessment of anthropometric measures}

Weight and height of participants were determined in an overnight fasting status using a standard scale (Seca, Hamburg, Germany) at the beginning of the study and after 12-weeks' intervention. BMI was calculated as weight in $\mathrm{kg}$ divided by height in meters squared. All anthropometric measures were done by a trained staff at the gynecology clinic.

\subsection{Assessment of outcomes}

In our study, gene expression of $\mathrm{Lp}(\mathrm{a})$ and $\mathrm{Ox}-\mathrm{LDL}$, and biomarkers of oxidative stress were considered as the primary outcome, and body weight and changes in clinical characteristics of hyperandrogenism were considered as the secondary outcomes.

\subsection{Isolation of lymphocyte cells}

At first, $10 \mathrm{~mL}$ blood samples were obtained from participants at the onset of the study and 12 weeks after intervention. Then, lymphocyte cells were extracted from blood samples of women with PCOS using a 50\% percoll (Sigma-Aldrich, Dorset, UK) gradient. Thus, for preparing a stock isotonic percoll solution, osmolity of the solution was adjusted by adding 1 part of $10 \times$ concentrated cell culture medium into the 9 parts of percoll. Osmolality of the stock solution was checked by osmometer model 3300 (LabX, EI Cajon, USA). Solution of stock isotonic percoll (SIP) was diluted by adding normal cell culture medium. The cells of lymphocytes which were at the interface of percoll and serum were removed by using a pasteur pipette and washed a few times with phosphate buffer saline (PBS). Samples were taken for cell count and viability testing by trypan blue, RNA and DNA extraction.

\subsection{Total RNA extraction}

In order to RNA extraction, the RNXplus kit (Cinnacolon, Tehran, Iran) was used. Total RNA extraction from all prepared samples was done as recommended protocol by manufacture. After preparation of homogenate, the cells powder was harvested and re-suspended in $1 \mathrm{ml}$ of RNAXplus reagent in a clean RNase-free tube. After incubation for $5 \mathrm{~min}$ at room temperature, the sample was pipetted and subsequently treated with addition of $200 \mu \mathrm{l}$ of chloroform. The mixture incubated at room temperature for 5 min after shaking rigorously for $15 \mathrm{~s}$. The mixture was centrifuged at $12,000 \mathrm{~g}$ for 15 min and the aqueous phase containing the RNA was transferred to a clean RNase-free tube. The total RNA was precipitated at room temperature for $15 \mathrm{~min}$. The pellet including total RNA was washed by using $75 \%$ ethanol and centrifuge at $7500 \mathrm{~g}$ for $8 \mathrm{~min}$. After drying ethanol, the RNA pellet re-suspended in $50 \mu \mathrm{l}$ or less of TE buffer. The concentration of total RNA was calculated based on OD $260 / 280$ ration measurements as a means to means to address purity of RNA. To confirm the integrity of extracted RNA, it was electrophoresed. RNA suspension was frozen in $-20^{\circ} \mathrm{C}$ until cDNA making. Following the extraction of the total RNAs from each sample, RNA quantification were performed by UV spectrophotometer. Each samples OD 260/280 ratio between 1.7 and 2.1 was intended that shows no contamination with both protein and DNA.

\subsection{First strand $c D N A$ synthesis procedure}

The first strand cDNA synthesis can be performed as an individual reaction or as a series of parallel reactions with different RNA templates. Therefore, the reaction mixture can be provided by merging reagents individually or a master mix can be prepared all of the components except template RNA. Depending on the structure of RNA templates, separate steps for RNA denaturation and primer annealing many improve RT-PCR results. The isolated RNA was reverse transcribed to cDNA library using moloney murine leukemia virus (MMLV) reverse transcriptase (RT). Reverse transcription was performed with random primers.

\subsection{Gene expression}

Expressed levels of $\mathrm{Lp}(\mathrm{a})$ and $\mathrm{Ox}-\mathrm{LDL}$ were evaluated by quantitative RT-PCR, using the LightCycler technology (Roche Diagnostics, Rotkreuz, Switzerland) with SYBR green detection and Amplicon Kit (Table 1). Glyceraldehyde-3-phosphate dehydrogenase (GAPDH) primers were used as a loading control (forward: AAGCTCATTTCCTGGTATGACAACG; reverse: TCTTCCTCTTGTGCTCTTGCTGG). As template, approximately $50 \mathrm{ng}$ cDNA was applied in a quantitative real-time RT-PCR, and the signals were detected using a real-time PCR system. All reactions were run in duplicates. All primers were designed using Primer Express Software (Applied Biosystems) and Beacon designer software then, purchased from Takaposizt Company- IRAN. Relative transcription levels were calculated using Pffafi method or $2^{-\Delta \Delta C T}$. Normalization of gene expression data is used to correct sample-to-sample variation. Starting material obtained from different individuals usually varies in tissue mass or cell number, RNA integrity or quantity, or experimental treatment. The ideal control gene should be expressed in an unchanging fashion regardless of experimental conditions, including different tissue or cell types, developmental stage, or sample treatment. Because there is no one gene that meets this criterion for every experimental condition, it is necessary to validate the expression stability of a control gene for the specific requirements of an experiment prior to its use for normalization. Also, GAPDH gene (housekeeping gene) was used for normalization.

\subsection{Clinical assessments}

Clinical assessments included determinations of hirsutism using a mFG scoring system (Hatch et al., 1981), of acne score (Kolodziejczyk et al., 2000) and of alopecia based on assessment guidelines collated by Olsen et al. (Olsen et al., 2004) in the current study. Acne was marked by a four-point scale: 0 , no acne; 1 , minor acne on face; 2 , moderate acne on face only; and 3, severe acne, face and back or chest (Kolodziejczyk et al., 2000).

\subsection{Biochemical assessment}

Ten milliliters fasting blood samples were taken at the beginning of the study and after 12 -week intervention at Kashan reference laboratory in a fasting status and centrifuged to separate serum. Then, the samples were stored at $-80^{\circ} \mathrm{C}$ before analysis. Enzymatic kits (Pars Azmun, Tehran, Iran) were used to quantify serum triglycerides, VLDL-, total-, LDL- and HDL-cholesterol concentrations. Total-/HDL-cholesterol ratio was calculated as total cholesterol divided by HDL-cholesterol. All inter- and intra-assay coefficient variances (CVs) for lipid concentrations were less than 5\%. Plasma total antioxidant capacity (TAC) concentrations were determined by the method of ferric reducing antioxidant power developed by Benzie and Strain (Benzie and Strain, 1996), total 
Table 1

Specific primers used for real-time quantitative PCR.

\begin{tabular}{|c|c|c|c|}
\hline Gene & Primer & Product size (bp) & Annealing temperature $(\mathrm{C})$ \\
\hline \multirow{2}{*}{ GAPDH } & F: AAGCTCATTTCCTGGTATGACAACG & 126 & 61.3 \\
\hline & R: TCTTCCTCTTGTGCTCTTGCTGG & & \\
\hline \multirow[t]{2}{*}{$\operatorname{Lp}(a)$} & F: GACACAGCACGTTCATTCCA & 55 & 200 \\
\hline & R: ACACCCCCCTACAATGCTTC & & \\
\hline \multirow[t]{2}{*}{ Ox-LDL } & F: ACTTACGGACAGACAGACAG & 57 & 223 \\
\hline & R: GGCCACACATCCCATGATTC & & \\
\hline
\end{tabular}

GAPDH, glyceraldehyde-3-Phosphate dehydrogenase; Lp(a), lipoprotein(a); Ox-LDL, oxidized low-density lipoprotein.

glutathione (GSH) were determined using the method of Beutler et al (Beutler and Gelbart, 1985). and malondialdehyde (MDA) concentrations were determined by the thiobarbituric acid reactive substances spectrophotometric test (Janero, 1990). All inter- and intra-assay CVs for TAC, GSH and MDA concentrations were less than $5 \%$. Commercial kits were used to quantify serum follicularstimulating hormone (FSH) and luteinizing hormone (LH) concentrations (Pars Azmun, Tehran, Iran). Inter- and intra-assay CVs for FSH and $\mathrm{LH}$ measurements were less than $7 \%$.

\subsection{Sample size}

Using a formula suggested for clinical trials, having 29 participants in each group were adequate while considering a type one error $(\alpha)$ of 0.05 and type two error $(\beta)$ of 0.20 (power $=80 \%$ ), $41.5 \mathrm{mg} / \mathrm{dL}$ as SD and $31.0 \mathrm{mg} / \mathrm{dL}$ as the mean distinction (d) of triglycerides as the key variable (Taghizadeh et al., 2016). Assuming 5 dropouts in each group, the final sample size was determined to be 34 participants in each group.

\subsection{Randomization}

Randomization assignment was done by the use of computergenerated random numbers. Randomization and allocation were concealed from the researchers and patients until the final analyses were completed. The randomized allocation sequence, enrolling participants and allocating them to interventions were conducted by a trained midwife at the gynecology clinic.

\subsection{Statistical methods}

To evaluate whether the study variables had normally distributed or not, we used the Kolmogrov-Smirnov test. To detect differences in anthropometric measures as well as in macro- and micro-nutrient dietary intakes between the two groups, we applied Student's $t$-test to independent samples. Differences in proportions were evaluated by Chi square test or Fisher's exact tests. To determine the effects of omega- 3 fatty acids and vitamin $\mathrm{E}$ co-supplementation on gene expression of Lp(a) and Ox-LDL, lipid profiles and biomarkers of oxidative stress, we used one-way repeated measures analysis of variance. To identify within-group differences (pre- and post-supplementation), we used pairedsamples t-tests. Adjustment for changes in baseline values of biochemical parameters, age and BMI at the baseline was performed by analysis of covariance (ANCOVA) using general linear models. The P-value of $<0.05$ were considered statistically significant. All statistical analyses used the Statistical Package for Social Science version 18 (SPSS Inc., Chicago, Illinois, USA).

\section{Results}

Among participants in the combined omega- 3 fatty acids and vitamin E group, 3 patients [due to pregnancy $(n=3)$ ] and in the placebo group, 2 patients [withdrawn for personal reasons $(\mathrm{n}=2)$ ] were excluded (Fig. 1). At the end, 68 patients with PCOS [omega-3 fatty acids plus vitamin $\mathrm{E}(\mathrm{n}=34)$ and placebo $(\mathrm{n}=34)$ ] completed the trial. However, as the analysis was based on the ITT principle, all 68 patients (34 in each group) were included in the final analyses.

Mean age, height, weight and BMI at the baseline and end-oftrial, alopecia and acne rate, and METs at the baseline and endof-trial were not statistically different between the two groups (Table 2).

Based on the 3-day dietary records obtained at the baseline, end-of-trial and throughout the trial, we found no significant difference in mean dietary macro- and micro-nutrient intakes between the two groups (Table 3).

Quantitative results of RT-PCR demonstrated that compared with the placebo, omega-3 fatty acids and vitamin E cosupplementation downregulated expressed levels of Lp(a) mRNA $(\mathrm{P}<0.001)$ in peripheral blood mononuclear cells of PCOS women (Fig. 2).

A significant change in expressed levels of Ox-LDL mRNA $(\mathrm{P}<0.001)$ in peripheral blood mononuclear cells of PCOS women following the supplementation of omega-3 fatty acids plus vitamin E compared with the placebo (Fig. 3).

After 12 weeks of intervention, compared to the placebo group, omega-3 fatty acids and vitamin E co-supplementation resulted in a significant decrease in serum triglycerides $(-22.1 \pm 22.3$ vs. $+7.7 \pm 23.6 \mathrm{mg} / \mathrm{dL}, \quad \mathrm{P}<0.001)$, VLDL- $(-4.4 \pm 4.5$ vs. $+1.5 \pm 4.7 \mathrm{mg} / \mathrm{dL}, \quad \mathrm{P}<0.001)$, total- $(-20.3 \pm 16.6$ vs. $+12.2 \pm 26.1 \mathrm{mg} / \mathrm{dL}, \quad \mathrm{P}<0.001)$, LDL- $(-16.7 \pm 15.3$ vs. $+11.9 \pm 26.1 \mathrm{mg} / \mathrm{dL}, \mathrm{P}<0.001)$ and total-/HDL-cholesterol $(-0.5 \pm 0.6$ vs. $+0.4 \pm 0.8, \mathrm{P}<0.001)$ (Table 4$)$. There were a significant increase in plasma TAC $(+89.4 \pm 108.9$ vs. $+5.9 \pm 116.2 \mathrm{mmol} / \mathrm{L}, \mathrm{P}=0.003)$ and a significant decrease in MDA levels $(-0.3 \pm 0.4$ vs. $-0.008 \pm 0.6 \mu \mathrm{mol} / \mathrm{L}, \mathrm{P}=0.01)$ by combined omega- 3 fatty acids and vitamin $\mathrm{E}$ intake compared with the placebo group. We did not observe any significant effect of omega-3 fatty acids and vitamin E co-supplementation on serum HDLcholesterol, plasma GSH, serum FSH and LH levels.

However, after adjustment for baseline values of biochemical parameters, age and baseline BMI no significant changes in our findings occurred, except for plasma TAC $(\mathrm{P}=0.38)$ and MDA levels $(\mathrm{P}=0.99)$ (Table 5).

\section{Discussion}

In the current study, which to the best of our knowledge is the first of its kind, we evaluated effects of omega- 3 fatty acids and vitamin E co-supplementation on gene expression of $\mathrm{LP}(\mathrm{a})$ and $\mathrm{Ox}$ LDL, lipid profiles and biomarkers of oxidative stress among patients with PCOS. We demonstrated that omega-3 fatty acids and vitamin E co-supplementation for 12 weeks among PCOS women had beneficial effects on gene expression of $\mathrm{LP}(\mathrm{a})$ and $\mathrm{Ox}-\mathrm{LDL}$, serum triglycerides, VLDL-, total-, LDL- and total-/HDL-cholesterol, plasma TAC and MDA levels; but it did not had any effect on 


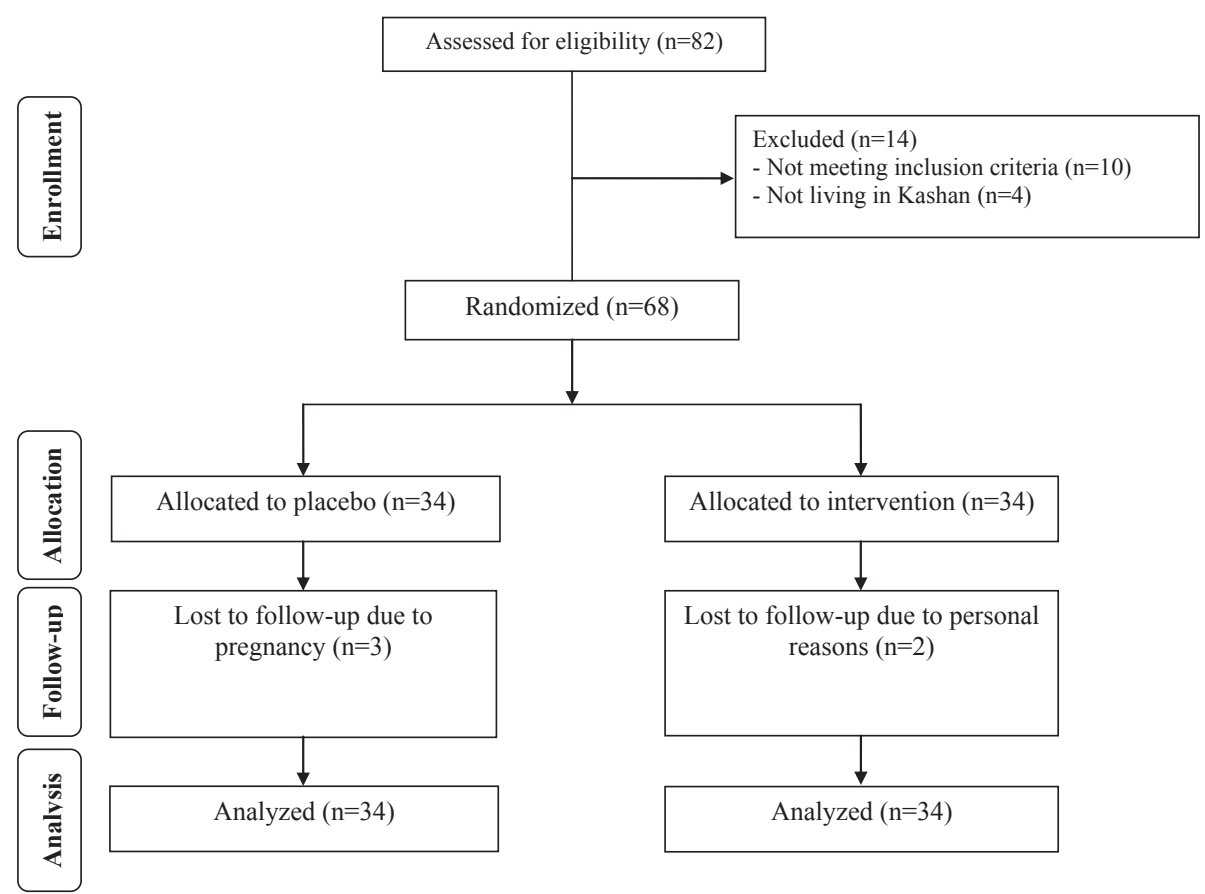

Fig. 1. Summary of patient flow diagram.

Table 2

General characteristics of study participants.

\begin{tabular}{|c|c|c|c|}
\hline & Placebo group $(\mathrm{n}=34)$ & Omega-3 fatty acids plus vitamin E group $(\mathrm{n}=34)$ & $\mathrm{P}^{\mathrm{a}}$ \\
\hline Age $(y)$ & $26.6 \pm 5.6$ & $24.9 \pm 5.5$ & 0.20 \\
\hline Height $(\mathrm{cm})$ & $163.3 \pm 6.9$ & $161.8 \pm 6.2$ & 0.35 \\
\hline Weight at study baseline (kg) & $77.6 \pm 18.2$ & $74.1 \pm 10.7$ & 0.33 \\
\hline Weight at end-of-trial (kg) & $77.4 \pm 18.3$ & $73.8 \pm 10.8$ & 0.31 \\
\hline Weight change $(\mathrm{kg})$ & $-0.2 \pm 1.1$ & $-0.3 \pm 1.1$ & 0.57 \\
\hline BMI at study baseline $\left(\mathrm{kg} / \mathrm{m}^{2}\right)$ & $29.0 \pm 6.5$ & $28.4 \pm 4.4$ & 0.61 \\
\hline BMI at end-of-trial $\left(\mathrm{kg} / \mathrm{m}^{2}\right)$ & $29.0 \pm 6.5$ & $28.2 \pm 4.6$ & 0.59 \\
\hline BMI change $\left(\mathrm{kg} / \mathrm{m}^{2}\right)$ & $-0.1 \pm 0.4$ & $-0.1 \pm 0.4$ & 0.62 \\
\hline MET-h/day at study baseline & $28.9 \pm 2.3$ & $29.4 \pm 2.5$ & 0.33 \\
\hline MET-h/day at end-of-trial & $28.8 \pm 2.3$ & $29.5 \pm 2.5$ & 0.26 \\
\hline MET-h/day change & $-0.1 \pm 0.8$ & $0.1 \pm 0.8$ & 0.59 \\
\hline Decreased alopecia (\%) & $1(4.5)$ & $4(22.2)$ & $0.09^{b}$ \\
\hline Decreased acne (\%) & $2(9.1)$ & $5(23.8)$ & $0.19^{b}$ \\
\hline
\end{tabular}

Data are means \pm SDs.

a Obtained from independent $t$-test. METs, metabolic equivalents.

b Obtained from Pearson Chi-square tests.

Table 3

Dietary intakes of study participants throughout the study.

\begin{tabular}{|c|c|c|c|}
\hline & Placebo group $(\mathrm{n}=34)$ & Omega-3 fatty acids plus vitamin E group $(\mathrm{n}=34)$ & $\mathrm{P}^{\mathrm{a}}$ \\
\hline Energy $(\mathrm{kcal} / \mathrm{d})$ & $2511 \pm 173$ & $2524 \pm 174$ & 0.76 \\
\hline Carbohydrates (g/d) & $347.9 \pm 33.5$ & $354.2 \pm 47.0$ & 0.53 \\
\hline Protein $(\mathrm{g} / \mathrm{d})$ & $90.1 \pm 11.7$ & $91.1 \pm 15.5$ & 0.76 \\
\hline Fat $(\mathrm{g} / \mathrm{d})$ & $88.0 \pm 12.6$ & $86.3 \pm 13.8$ & 0.59 \\
\hline SFAs $(\mathrm{g} / \mathrm{d})$ & $26.4 \pm 4.9$ & $27.1 \pm 5.5$ & 0.44 \\
\hline PUFAs (g/d) & $27.1 \pm 6.7$ & $27.7 \pm 5.9$ & 0.66 \\
\hline MUFAs (g/d) & $24.4 \pm 6.8$ & $24.0 \pm 5.5$ & 0.78 \\
\hline Cholesterol (mg/d) & $214.0 \pm 106.0$ & $215.3 \pm 100.7$ & 0.96 \\
\hline TDF $(g / d)$ & $20.0 \pm 4.7$ & $20.6 \pm 4.9$ & 0.62 \\
\hline Omega-3 (g/d) & $1.0 \pm 0.1$ & $1.1 \pm 0.2$ & 0.30 \\
\hline
\end{tabular}

Data are means \pm SDs.

MUFAs, monounsaturated fatty acids; PUFAs, polyunsaturated fatty acids; SFAs, saturated fatty acids; TDF, total dietary fiber.

a Obtained from independent $t$-test. 


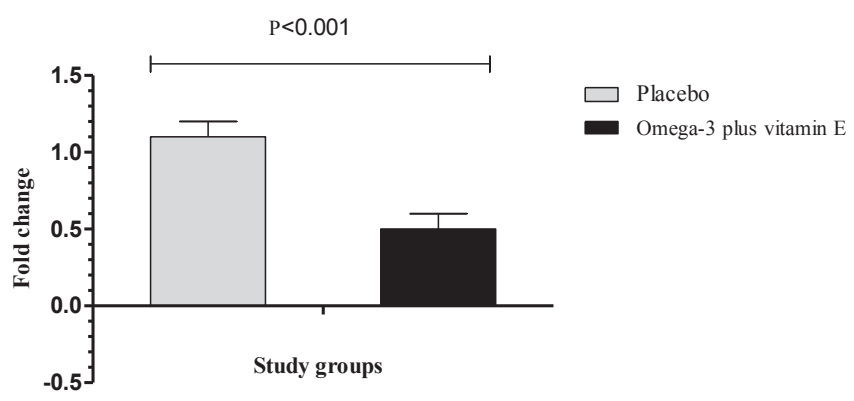

Fig. 2. Effect of 12-week supplementation with omega-3 fatty acids plus vitamin E or placebo on expression ratio of $\mathrm{LP}(\mathrm{a})$ gene in blood mononuclear cells of PCOS women. $P$ value was obtained from independent samples Student's $t$-test. Data are means \pm standard deviation.

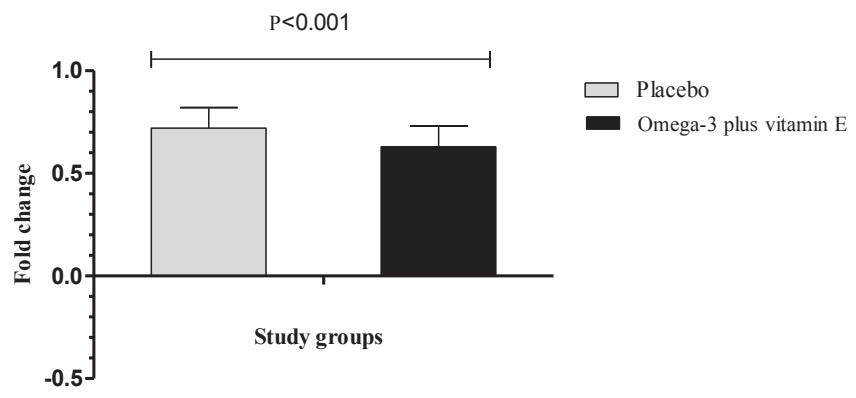

Fig. 3. Effect of 12-week supplementation with omega-3 fatty acids plus vitamin E or placebo on expression ratio of Ox-LDL gene in blood mononuclear cells of PCOS women. P value was obtained from independent samples Student's $t$-test. Data are means \pm standard deviation. Lp(a), lipoprotein(a); Ox-LDL, oxidized low-density lipoprotein; PCOS, polycystic ovary syndrome. formation (Huang et al., 2012). Previous genetic and epidemiologic studies have demonstrated that $\operatorname{Lp}(\mathrm{a})$ is as a risk factor for atherosclerotic diseases such as CHD and stroke (Nordestgaard et al., 2010; Steinberg and Witztum, 2010; Kamstrup et al., 2011). Omega-3 fatty acids and vitamin E intake may reduce $L p(a)$ and OxLDL expression through inhibiting phosphatidylinosinitol 3-kinase and protein kinase B (PKB) pathway (Chen et al., 2003) and modulating the activities of oxidative stress-induced NF- $\kappa \mathrm{B}$ pathway (Huang et al., 2012).

Our study demonstrated that omega-3 fatty acids and vitamin E co-supplementation for 12 weeks in PCOS women had the beneficial effects on lipid profiles except HDL-cholesterol levels compared with the placebo. In agreement with our study, supplementation with $3.5 \mathrm{~g} /$ day flaxseed oil for 6 weeks decreased triglycerides levels among PCOS women (Vargas et al., 2011). In addition, $4 \mathrm{~g} /$ day omega- 3 fatty acids supplementation significantly decreased serum total- and LDL-cholesterol among PCOS women for 8 weeks (Mohammadi et al., 2012). Our previous study among GDM women indicated that $1000 \mathrm{mg}$ omega- 3 fatty acids from flaxseed oil plus $400 \mathrm{IU}$ vitamin E co-supplementation for 6 weeks led to significant differences in serum triglycerides, VLDL-, LDL- and HDL-cholesterol levels (Taghizadeh et al., 2016). However, no significant change in lipid profiles was seen following the consumption of combined omega-3 fatty acids from fish oil and vitamin $\mathrm{E}$ among hemodialysis patients for 12 weeks (Karamali et al., 2016). Lemos et al. (2012) also reported that taking $2 \mathrm{~g} /$ day flaxseed oil among hemodialysis patients for 4 months did not affect triglycerides concentrations. Supplementation with three different dosages of tocopherol (100 IU/day, $200 \mathrm{IU} /$ day, and $300 \mathrm{IU} /$ day) for 4 months in women with metabolic syndrome was also associated with a significant decrease in total cholesterol levels, but triglycerides concentrations were unaltered (Wang et al., 2010). Pre-

Table 4

Lipid profiles and biomarkers of oxidative stress at the study baseline and after 12 weeks of the intervention in patients with polycystic ovary syndrome.

\begin{tabular}{|c|c|c|c|c|c|c|c|c|c|}
\hline & \multicolumn{4}{|c|}{ Placebo group $(\mathrm{n}=34)$} & \multicolumn{4}{|c|}{ Omega-3 fatty acids plus vitamin E group $(\mathrm{n}=34)$} & \multirow[t]{2}{*}{$\mathrm{P}^{\mathrm{b}}$} \\
\hline & Baseline & End-of-trial & Change & $\mathrm{P}^{\mathrm{a}}$ & Baseline & End-of-trial & Change & $\mathrm{P}^{\mathrm{a}}$ & \\
\hline Triglycerides (mg/dL) & $120.6 \pm 59.4$ & $128.3 \pm 72.6$ & $7.7 \pm 23.6$ & 0.06 & $122.7 \pm 61.7$ & $100.6 \pm 54.0$ & $-22.1 \pm 22.3$ & $<0.001$ & $<0.001$ \\
\hline VLDL-cholesterol (mg/dL) & $24.1 \pm 11.9$ & $25.7 \pm 14.5$ & $1.5 \pm 4.7$ & 0.06 & $24.5 \pm 12.3$ & $20.1 \pm 10.8$ & $-4.4 \pm 4.5$ & $<0.001$ & $<0.001$ \\
\hline Total cholesterol (mg/dL) & $166.4 \pm 29.2$ & $178.6 \pm 29.9$ & $12.2 \pm 26.1$ & 0.01 & $181.8 \pm 28.0$ & $161.5 \pm 31.4$ & $-20.3 \pm 16.6$ & $<0.001$ & $<0.001$ \\
\hline LDL-cholesterol (mg/dL) & $92.9 \pm 25.5$ & $104.8 \pm 26.3$ & $11.9 \pm 26.1$ & 0.01 & $111.1 \pm 26.5$ & $94.4 \pm 29.8$ & $-16.7 \pm 15.3$ & $<0.001$ & $<0.001$ \\
\hline HDL-cholesterol (mg/dL) & $49.4 \pm 8.1$ & $48.1 \pm 9.3$ & $-1.3 \pm 6.3$ & 0.24 & $46.2 \pm 10.0$ & $47.0 \pm 9.5$ & $0.8 \pm 3.6$ & 0.18 & 0.09 \\
\hline Total-/HDL-cholesterol & $3.5 \pm 0.8$ & $3.9 \pm 1.1$ & $0.4 \pm 0.8$ & 0.007 & $4.1 \pm 1.0$ & $3.6 \pm 0.9$ & $-0.5 \pm 0.6$ & $<0.001$ & $<0.001$ \\
\hline $\mathrm{TAC}(\mathrm{mmol} / \mathrm{L})$ & $969.5 \pm 85.3$ & $975.4 \pm 98.0$ & $5.9 \pm 116.2$ & 0.77 & $860.5 \pm 101.0$ & $949.9 \pm 119.3$ & $89.4 \pm 108.9$ & $<0.001$ & 0.003 \\
\hline $\mathrm{GSH}(\mu \mathrm{mol} / \mathrm{L})$ & $511.8 \pm 69.1$ & $555.2 \pm 62.4$ & $43.3 \pm 66.3$ & 0.001 & $525.3 \pm 84.1$ & $544.8 \pm 81.3$ & $19.5 \pm 39.3$ & 0.007 & 0.07 \\
\hline $\operatorname{MDA}(\mu \mathrm{mol} / \mathrm{L})$ & $2.2 \pm 0.5$ & $2.2 \pm 0.5$ & $-0.008 \pm 0.6$ & 0.93 & $2.9 \pm 0.6$ & $2.5 \pm 0.6$ & $-0.3 \pm 0.4$ & $<0.001$ & 0.01 \\
\hline $\mathrm{FSH}(\mathrm{IU} / \mathrm{L})$ & $7.9 \pm 2.8$ & $8.1 \pm 3.2$ & $0.2 \pm 3.0$ & 0.67 & $7.3 \pm 2.5$ & $7.2 \pm 2.5$ & $-0.1 \pm 3.5$ & 0.86 & 0.68 \\
\hline $\mathrm{LH}(\mathrm{IU} / \mathrm{L})$ & $13.5 \pm 13.3$ & $11.4 \pm 7.7$ & $-2.1 \pm 13.3$ & 0.35 & $11.0 \pm 8.0$ & $10.5 \pm 8.9$ & $-0.5 \pm 10.1$ & 0.77 & 0.56 \\
\hline
\end{tabular}

All values are means \pm SDs.

FSH, follicle-stimulating hormone; GSH, total glutathione; LH, luteinizing hormone; MDA, malondialdehyde; TAC, total antioxidant capacity.

a $\mathrm{P}$ values represent paired-samples $t$-test.

b $\mathrm{P}$ values represent the time $\times$ group interaction (computed by analysis of the one-way repeated measures ANOVA).

HDL-cholesterol and GSH concentrations.

Patients with PCOS are susceptible to several aberrations including metabolic disorders and oxidative stress (Asemi and Esmaillzadeh, 2015; Asemi et al., 2015). The current study shown that joint omega-3 fatty acids and vitamin E supplementation for 12 weeks in PCOS women downregulated $\mathrm{LP}(\mathrm{a})$ and Ox-LDL expression. In agreement with our findings, in a study by Chen et al. (2003) was seen that both docosahexaenoic acid (DHA) and eicosapentaenoic acid (EPA) decreased ox-LDL-induced upregulation of in human coronary artery endothelial cells. Furthermore, vitamin $\mathrm{E}$ ameliorated ox-LDL-induced foam cell macrophages vious studies have demonstrated that hyperandrogenism (Macut et al., 2013), impaired glucose tolerance, insulin resistance and ovarian dysfunction (Strowitzki et al., 2002) can result in increased lipid profiles. Altered lipid profiles in patients with PCOS may contribute to an increased risk for cardiovascular diseases and adiposity (Birdsall et al., 1997). In addition, subjects with PCOS are prone to oxidative stress induced by hyperglycemia, but this seems not to be related to the direct effect of hyperinsulinemia during clamp (Savic-Radojevic et al., 2015). Increased pro- and antioxidative indicators are associated with both insulin resistance and increased testosterone production (Savic-Radojevic et al., 
Table 5

Adjusted changes in metabolic profile of the patients with polycystic ovary syndrome.

\begin{tabular}{|c|c|c|c|}
\hline & Placebo group $(\mathrm{n}=34)$ & Omega-3 fatty acids plus vitamin E group $(\mathrm{n}=34)$ & $\mathrm{P}^{\mathrm{a}}$ \\
\hline Triglycerides (mg/dL) & $7.5 \pm 4.0$ & $-21.9 \pm 4.0$ & $<0.001$ \\
\hline VLDL-cholesterol (mg/dL) & $1.5 \pm 0.8$ & $-4.4 \pm 0.8$ & $<0.001$ \\
\hline Total cholesterol (mg/dL) & $10.0 \pm 3.8$ & $-18.1 \pm 3.8$ & $<0.001$ \\
\hline LDL-cholesterol (mg/dL) & $8.5 \pm 3.7$ & $-13.3 \pm 3.7$ & $<0.001$ \\
\hline HDL-cholesterol (mg/dL) & $-0.7 \pm 0.8$ & $0.2 \pm 0.8$ & 0.45 \\
\hline Total-/HDL-cholesterol ratio & $0.3 \pm 0.1$ & $-0.4 \pm 0.1$ & $<0.001$ \\
\hline TAC (mmol/L) & $35.0 \pm 19.2$ & $60.3 \pm 19.1$ & 0.38 \\
\hline $\mathrm{GSH}(\mu \mathrm{mol} / \mathrm{L})$ & $41.1 \pm 8.7$ & $21.7 \pm 8.7$ & 0.12 \\
\hline $\operatorname{MDA}(\mu \mathrm{mol} / \mathrm{L})$ & $-0.2 \pm 0.1$ & $-0.2 \pm 0.1$ & 0.99 \\
\hline FSH (IU/L) & $0.5 \pm 0.5$ & $-0.4 \pm 0.5$ & 0.20 \\
\hline $\mathrm{LH}(\mathrm{IU} / \mathrm{L})$ & $-1.5 \pm 0.5$ & $-1.2 \pm 1.4$ & 0.89 \\
\hline
\end{tabular}

All values are means \pm SEs. Values are adjusted for baseline values, age and BMI at baseline.

FSH, follicle-stimulating hormone; GSH, total glutathione; LH, luteinizing hormone; MDA, malondialdehyde; TAC, total antioxidant capacity.

a Obtained from ANCOVA.

2015). The molecular mechanisms underlying the effect of omega-3 fatty acids and vitamin $\mathrm{E}$ on lipid concentrations remain unclear, but several mechanisms have been proposed in related studies. Omega-3 fatty acids supplementation may decrease triglycerides and VLDL-cholesterol levels through reduced jejunal secretion of apoB-48 by increasing its posttranslational degradation (Levy et al., 2006), the improved postprandial clearance of chylomicrons (Harris and Bulchandani, 2006) and decreasing hepatic production of VLDL-cholesterol (Miyoshi et al., 2014). Increased hepatic of PPAR- $\alpha$ expression and decreased PPAR- $\gamma$ expression levels increase the utilization of lipids in the liver, which in turn would result in improved lipid profiles (Kim do et al., 2013).

Although worries about the consumption of omega- 3 fatty acids and increased lipid peroxidation have lingered about for some time, but this study indicated that omega-3 fatty acids plus vitamin E cosupplementation for 12 weeks in PCOS women resulted in a significant increase in plasma TAC and a significant decrease in MDA concentrations compared with the placebo, but unchanged GSH levels. In line with our findings, diet supplementation with $3 \mathrm{~g} /$ day omega- 3 fatty acids among atherosclerotic patients for 2 months decreased MDA levels (Hassan Eftekhari et al., 2013). Joint supplementation with $2 \mathrm{~g}$ omega-3 fatty acids and 400 IU vitamin E among patients with T2DM for 12 weeks led to a significant increase in TAC and a significant decrease in MDA levels (Sarbolouki et al., 2010). Similar findings were observed following the supplementation with $400 \mathrm{mg} /$ day vitamin $\mathrm{E}$ in subjects with T2DM for 3 months (Shinde et al., 2011), and $600 \mathrm{mg} /$ day vitamin $\mathrm{E}$ in patients with T1DM for 3 months (Gupta et al., 2011) and $2.7 \mathrm{~g} /$ day of pure EPA in overweight subjects with non-alcoholic steatohepatitis for 12 months (Tanaka et al., 2008). However, some researchers did not observe such beneficial effects on biomarkers of oxidative stress. For example, in a study by Cunnane et al. (1995) was seen no significant effect in lipid hydroperoxides concentrations following the consumption with flaxseed oil among healthy young adults for 4 weeks (Cunnane et al., 1995). In addition, no significant change in lipid peroxidation was observed after omega-3 fatty acids $(600 \mathrm{mg}$ EPA and 400 mg DHA per day) supplementation alone or in association with $30 \mathrm{mg}$ vitamin $\mathrm{E}, 60 \mathrm{mg}$ vitamin $C$ and $6 \mathrm{mg} \beta$-carotene in judoists for 6 weeks (Filaire et al., 2011). The increase of adipocytes in PCOS have been identified as a source of proinflammatory cytokines (Tan et al., 2006), which in turn act as a potent stimulator of the production of ROS and nitrogen species. Furthermore, NADPH oxidase is the major enzymatic source of free radicals in PCOS, which result in increased production of superoxide radicals in response to both hyperglycemia and increased levels of free fatty acids (Gonzalez et al., 2012). The increase of these components in PCOS are strongly associated with atherosclerosis and hypertension
(Gonzalez et al., 2006). The beneficial effects of combined omega-3 fatty acids and vitamin E supplementation on biomarkers of oxidative stress might be explained by their impacts on reducing the mitochondrial ROS production (Capo et al., 2015) and improved antioxidant defense system (Gupta et al., 2011). Although the effects of omega-3 fatty acids or vitamin E supplementation compared with statins, glitazones or other medications on amelioration of lipid profiles, and specially Lp(a) and Ox-LDL are interesting, to the best of our knowledge, data on these comparisons are scarce. Nevertheless, few studies have evaluated the effects of combined therapy of omega-3-fatty acids with lipidlowering agents on lipid profiles. For instance, in a study by Mindrescu et al. (2008) was observed that combined therapy with omega-3 fatty acids and rosuvastatin compared with only rosuvastatin ameliorated lipid profiles and endothelial function in South Asian subjects with dyslipidemia and endothelial dysfunction. Nonetheless, we believe that further studies are needed about the effect of omega-3 fatty acids and vitamin E supplementation compared with lipid-lowering agents on amelioration of lipid profiles in patients with PCOS.

The current study had few limitations. Due to budget limitations, we did not evaluate measurements of fatty acids profiles and vitamin E levels at study baseline and at the end-of-trial. Furthermore, we could not asses omega-3 fatty acids and vitamin E cosupplementation on expression levels of biomarkers of oxidative stress. It must be kept in mind that in the current study, we did not evaluate the effects of omega- 3 fatty acids and vitamin E cosupplementation on fasting plasma glucose, insulin, total testosterone and other steroids levels due to limited funding for research projects in developing countries. Therefore, assessment of these variables are warranted in future studies.

Overall, omega-3 fatty acids and vitamin E co-supplementation for 12 weeks in PCOS women significantly improved gene expression of $\mathrm{Lp}(\mathrm{a})$ and $\mathrm{Ox}-\mathrm{LDL}$, lipid profiles and biomarkers of oxidative stress.

\section{Author's contributions}

ZA contributed in conception, design, statistical analysis and drafting of the manuscript. ER, MS, FA-E, FF, ShA, MR, MJ, EA, FB, MT and MR-M contributed in data collection and manuscript drafting. All authors approved the final version for submission. ZA supervised the study.

\section{Conflicts of interest}

None declared. 


\section{Acknowledgments}

The current study was founded by a grant from the Vicechancellor for Research, KUMS and BPUMS, and Iran. The authors would like to thank the staff of Naghavi Clinic (Kashan, Iran) for their assistance on this project.

\section{Appendix A. Supplementary data}

Supplementary data related to this article can be found at http:// dx.doi.org/10.1016/j.mce.2016.09.008.

\section{References}

Ahmadi, A., Mazooji, N., Roozbeh, J., Mazloom, Z., Hasanzade, J., 2013. Effect of alpha-lipoic acid and vitamin E supplementation on oxidative stress, inflammation, and malnutrition in hemodialysis patients. Iran. J. Kidney Dis. 7 (6), $461-467$.

Ainsworth, B.E., Haskell, W.L., Whitt, M.C., Irwin, M.L., Swartz, A.M., Strath, S.J., O'Brien, W.L., Bassett Jr., D.R., Schmitz, K.H., Emplaincourt, P.O., Jacobs Jr., D.R., Leon, A.S., 2000. Compendium of physical activities: an update of activity codes and MET intensities. Med. Sci. Sports Exerc 32 (9 Suppl. 1), S498-S504.

Asemi, Z., Esmaillzadeh, A., 2015. DASH diet, insulin resistance, and serum hs-CRP in polycystic ovary syndrome: a randomized controlled clinical trial. Horm. Metab. Res. 47 (3), 232-238.

Asemi, Z., Foroozanfard, F., Hashemi, T., Bahmani, F., Jamilian, M., Esmaillzadeh, A., 2015. Calcium plus vitamin D supplementation affects glucose metabolism and lipid concentrations in overweight and obese vitamin D deficient women with polycystic ovary syndrome. Clin. Nutr. 34 (4), 586-592.

Benzie, I.F., Strain, J.J., 1996. The ferric reducing ability of plasma (FRAP) as a measure of "antioxidant power": the FRAP assay. Anal. Biochem. 239 (1), 70-76.

Beutler, E., Gelbart, T., 1985. Plasma glutathione in health and in patients with malignant disease. J. Lab. Clin. Med. 105 (5), 581-584.

Birdsall, M.A., Farquhar, C.M., White, H.D., 1997. Association between polycystic ovaries and extent of coronary artery disease in women having cardiac catheterization. Ann. Intern Med. 126 (1), 32-35.

Capo, X., Martorell, M., Sureda, A., Llompart, I., Tur, J.A., Pons, A., 2015. Diet supplementation with DHA-enriched food in football players during training season enhances the mitochondrial antioxidant capabilities in blood mononuclear cells. Eur. J. Nutr. 54 (1), 35-49.

Carlioglu, A., Kaygusuz, I., Karakurt, F., Gumus, I.I., Uysal, A., Kasapoglu, B., Armutcu, F., Uysal, S., Keskin, E.A., Koca, C., 2014. The platelet activating factor acetyl hydrolase, oxidized low-density lipoprotein, paraoxonase 1 and arylesterase levels in treated and untreated patients with polycystic ovary syndrome. Arch. Gynecol. Obstet. 290 (5), 929-935.

Chen, H., Li, D., Chen, J., Roberts, G.J., Saldeen, T., Mehta, J.L., 2003. EPA and DHA attenuate ox-LDL-induced expression of adhesion molecules in human coronary artery endothelial cells via protein kinase B pathway. J. Mol. Cell Cardiol. 35 (7), 769-775.

Conway, G., Dewailly, D., Diamanti-Kandarakis, E., Escobar-Morreale, H.F., Franks, S., Gambineri, A., Kelestimur, F., Macut, D., Micic, D., Pasquali, R., Pfeifer, M., Pignatelli, D., Pugeat, M., Yildiz, B.O., 2014. The polycystic ovary syndrome: a position statement from the European Society of Endocrinology. Eur. J. Endocrinol. 171 (4), P1-P29.

Cunnane, S.C., Hamadeh, M.J., Liede, A.C., Thompson, L.U., Wolever, T.M., Jenkins, D.J., 1995. Nutritional attributes of traditional flaxseed in healthy young adults. Am. J. Clin. Nutr. 61 (1), 62-68.

Duleba, A.J., Foyouzi, N., Karaca, M., Pehlivan, T., Kwintkiewicz, J., Behrman, H.R., 2004. Proliferation of ovarian theca-interstitial cells is modulated by antioxidants and oxidative stress. Hum. Reprod. 19 (7), 1519-1524.

Ehara, S., Ueda, M., Naruko, T., Haze, K., Itoh, A., Otsuka, M., Komatsu, R., Matsuo, T., Itabe, H., Takano, T., Tsukamoto, Y., Yoshiyama, M., Takeuchi, K., Yoshikawa, J., Becker, A.E., 2001. Elevated levels of oxidized low density lipoprotein show a positive relationship with the severity of acute coronary syndromes. Circulation 103 (15), 1955-1960.

El-Mazny, A., Abou-Salem, N., El-Sherbiny, W., 2010. Insulin resistance, dyslipidemia, and metabolic syndrome in women with polycystic ovary syndrome. Int. J. Gynaecol. Obstet. 109 (3), 239-241.

Filaire, E., Massart, A., Rouveix, M., Portier, H., Rosado, F., Durand, D., 2011. Effects of 6 weeks of n-3 fatty acids and antioxidant mixture on lipid peroxidation at rest and postexercise. Eur. J. Appl. Physiol. 111 (8), 1829-1839.

Gonzalez, F., Rote, N.S., Minium, J., Kirwan, J.P., 2006. Reactive oxygen speciesinduced oxidative stress in the development of insulin resistance and hyperandrogenism in polycystic ovary syndrome. J. Clin. Endocrinol. Metab. 91 (1), $336-340$.

Gonzalez, F., Nair, K.S., Daniels, J.K., Basal, E., Schimke, J.M., Blair, H.E., 2012. Hyperandrogenism sensitizes leukocytes to hyperglycemia to promote oxidative stress in lean reproductive-age women. J. Clin. Endocrinol. Metab. 97 (8), 2836-2843.

Grindflek, E., Sundvold, H., Lien, S., Rothschild, M.F., 2000. Rapid communication: physical and genetic mapping of the Peroxisome Proliferator Activated Receptor gamma (PPAR-gamma) gene to porcine chromosome 13. J. Anim. Sci. 78 (5), 1391-1392.

Gupta, S., Sharma, T.K., Kaushik, G.G., Shekhawat, V.P., 2011. Vitamin E supplementation may ameliorate oxidative stress in type 1 diabetes mellitus patients. Clin. Lab. 57 (5-6), 379-386.

Harris, W.S., Bulchandani, D., 2006. Why do omega-3 fatty acids lower serum triglycerides? Curr. Opin. Lipidol. 17 (4), 387-393.

Hassan Eftekhari, M., Aliasghari, F., Babaei-Beigi, M.A., Hasanzadeh, J., 2013. Effect of conjugated linoleic acid and omega-3 fatty acid supplementation on inflammatory and oxidative stress markers in atherosclerotic patients. ARYA Atheroscler. 9 (6), 311-318.

Hatch, R., Rosenfield, R.L., Kim, M.H., Tredway, D., 1981. Hirsutism: implications, etiology, and management. Am. J. Obstet. Gynecol. 140 (7), 815-830.

Huang, A., Brennan, K., Azziz, R., 2010. Prevalence of hyperandrogenemia in the polycystic ovary syndrome diagnosed by the National Institutes of Health 1990 criteria. Fertil. Steril. 93 (6), 1938-1941.

Huang, Z.G., Liang, C., Han, S.F., Wu, Z.G., 2012. Vitamin E ameliorates ox-LDLinduced foam cells formation through modulating the activities of oxidative stress-induced NF-kappaB pathway. Mol. Cell Biochem. 363 (1-2), 11-19.

Jamil, A.S., Alalaf, S.K., Al-Tawil, N.G., Al-Shawaf, T., 2015. A case-control observational study of insulin resistance and metabolic syndrome among the four phenotypes of polycystic ovary syndrome based on Rotterdam criteria. Reprod. Health 12, 7. http://dx.doi.org/10.1186/1742-4755-12-7.

Janero, D.R., 1990. Malondialdehyde and thiobarbituric acid-reactivity as diagnostic indices of lipid peroxidation and peroxidative tissue injury. Free Radic. Biol. Med. 9 (6), 515-540.

Kamstrup, P.R., Tybjaerg-Hansen, A., Nordestgaard, B.G., 2011. Lipoprotein(a) and risk of myocardial infarction-genetic epidemiologic evidence of causality. Scand. J. Clin. Lab. Invest. 71 (2), 87-93.

Karamali, M., Dadkhah, F., Sadrkhanlou, M., Jamilian, M., Ahmadi, S., TajabadiEbrahimi, M., Jafari, P., Asemi, Z., 2016. Effects of probiotic supplementation on glycaemic control and lipid profiles in gestational diabetes: a randomized, double-blind, placebo-controlled trial. Diabetes Metab. http://dx.doi.org/ 10.1016/j.diabet.2016.04.009.

Kim do, Y., Kim, J., Ham, H.J., Choue, R., 2013. Effects of d-alpha-tocopherol supplements on lipid metabolism in a high-fat diet-fed animal model. Nutr. Res. Pract. 7 (6), 481-487.

Kolodziejczyk, B., Duleba, A.J., Spaczynski, R.Z., Pawelczyk, L., 2000. Metformin therapy decreases hyperandrogenism and hyperinsulinemia in women with polycystic ovary syndrome. Fertil. Steril. 73 (6), 1149-1154.

Kursawe, R., Narayan, D., Cali, A.M., Shaw, M., Pierpont, B., Shulman, G.I., Caprio, S., 2010. Downregulation of ADIPOQ and PPARgamma2 gene expression in subcutaneous adipose tissue of obese adolescents with hepatic steatosis. Obes. (Silver Spring) 18 (10), 1911-1917.

Legro, R.S., Kunselman, A.R., Dunaif, A., 2001. Prevalence and predictors of dyslipidemia in women with polycystic ovary syndrome. Am. J. Med. 111 (8), 607-613.

Lemos, J.R., Alencastro, M.G., Konrath, A.V., Cargnin, M., Manfro, R.C., 2012. Flaxseed oil supplementation decreases C-reactive protein levels in chronic hemodialysis patients. Nutr. Res. 32 (12), 921-927.

Levy, E., Spahis, S., Ziv, E., Marette, A., Elchebly, M., Lambert, M., Delvin, E., 2006. Overproduction of intestinal lipoprotein containing apolipoprotein B-48 in Psammomys obesus: impact of dietary n-3 fatty acids. Diabetologia 49 (8), 1937-1945.

Liepa, G.U., Sengupta, A., Karsies, D., 2008. Polycystic ovary syndrome (PCOS) and other androgen excess-related conditions: can changes in dietary intake make a difference? Nutr. Clin. Pract. 23 (1), 63-71.

Macut, D., Damjanovic, S., Panidis, D., Spanos, N., Glisic, B., Petakov, M., Rousso, D., Kourtis, A., Bjekic, J., Milic, N., 2006. Oxidised low-density lipoprotein concentration - early marker of an altered lipid metabolism in young women with PCOS. Eur. J. Endocrinol. 155 (1), 131-136.

Macut, D., Bjekic-Macut, J., Savic-Radojevic, A., 2013. Dyslipidemia and oxidative stress in PCOS. Front. Horm. Res. 40, 51-63.

Mindrescu, C., Gupta, R.P., Hermance, E.V., DeVoe, M.C., Soma, V.R., Coppola, J.T., Staniloae, C.S., 2008. Omega-3 fatty acids plus rosuvastatin improves endothelial function in South Asians with dyslipidemia. Vasc. Health Risk Manag. 4 (6), 1439-1447.

Miyoshi, T., Noda, Y., Ohno, Y., Sugiyama, H., Oe, H., Nakamura, K., Kohno, K., Ito, H. 2014. Omega-3 fatty acids improve postprandial lipemia and associated endothelial dysfunction in healthy individuals-a randomized cross-over trial. Biomed. Pharmacother. 68 (8), 1071-1077.

Mohammadi, E., Rafraf, M., Farzadi, L., Asghari-Jafarabadi, M., Sabour, S., 2012. Effects of omega-3 fatty acids supplementation on serum adiponectin levels and some metabolic risk factors in women with polycystic ovary syndrome. Asia Pac J. Clin. Nutr. 21 (4), 511-518.

Nordestgaard, B.G., Chapman, M.J., Ray, K., Boren, J., Andreotti, F., Watts, G.F., Ginsberg, H., Amarenco, P., Catapano, A., Descamps, O.S., Fisher, E., Kovanen, P.T., Kuivenhoven, J.A., Lesnik, P., Masana, L., Reiner, Z., Taskinen, M.R., Tokgozoglu, L., Tybjaerg-Hansen, A., 2010. Lipoprotein(a) as a cardiovascular risk factor: current status. Eur. Heart J. 31 (23), 2844-2853.

Olsen, E.A., Hordinsky, M.K., Price, V.H., Roberts, J.L., Shapiro, J., Canfield, D. Duvic, M., King Jr., L.E., McMichael, A.J., Randall, V.A., Turner, M.L., Sperling, L. Whiting, D.A., Norris, D., 2004. Alopecia areata investigational assessment guidelines-Part II. National Alopecia Areata Foundation. J. Am. Acad. Dermatol 
51 (3), 440-447.

Ramezani, A., Koohdani, F., Djazayeri, A., Nematipour, E., Keshavarz, S.A., SaboorYaraghi, A.A., Eshraghian, M.R., Yousefinejad, A., Javanbakht, H., Zarei, M., Gholamhosseini, S., Djalali, M., 2015. Effects of administration of omega-3 fatty acids with or without vitamin $\mathrm{E}$ supplementation on adiponectin gene expression in PBMCs and serum adiponectin and adipocyte fatty acid-binding protein levels in male patients with CAD. Anatol. J. Cardiol. 15 (12), 981-989.

Rotterdam ESHRE/ASRM-Sponsored PCOS Consensus Workshop Group, 2004 Revised 2003 consensus on diagnostic criteria and long-term health risks related to polycystic ovary syndrome. Fertil. Steril. 81 (1), 19-25.

Sarbolouki, S., Djalali, M., Dorosty, A., Djazayery, S., Eshraghian, M., Ebadi, S. Hashemi, S., 2010. Effects of EPA and vitamin E on serum enzymatic antioxidants and peroxidation indices in patients with type II diabetes mellitus. Iran. J. Public Health 39 (3), 82-91.

Savic-Radojevic, A., Bozic Antic, I., Coric, V., Bjekic-Macut, J., Radic, T., Zarkovic, M., Djukic, T., Pljesa-Ercegovac, M., Panidis, D., Katsikis, I., Simic, T., Macut, D., 2015 Effect of hyperglycemia and hyperinsulinemia on glutathione peroxidase activity in non-obese women with polycystic ovary syndrome. Horm. (Athens) 14 (1), 101-108.

Shinde, S.N., Dhadke, V.N., Suryakar, A.N., 2011. Evaluation of oxidative stress in type 2 diabetes mellitus and follow-up along with vitamin E supplementation. Indian J. Clin. Biochem. 26 (1), 74-77.

Steinberg, D., Witztum, J.L., 2010. Oxidized low-density lipoprotein and atherosclerosis. Arterioscler. Thromb. Vasc. Biol. 30 (12), 2311-2316.

Strowitzki, T., Halser, B., Demant, T., 2002. Body fat distribution, insulin sensitivity, ovarian dysfunction and serum lipoproteins in patients with polycystic ovary syndrome. Gynecol. Endocrinol. 16 (1), 45-51.

Taghizadeh, M., Jamilian, M. Mazloomi, M., Sanami, M., Asemi, Z, 2016. A randomized-controlled clinical trial investigating the effect of omega-3 fatty acids and vitamin E co-supplementation on markers of insulin metabolism and lipid profiles in gestational diabetes. J. Clin. Lipidol. 10 (2), 386-393.

Tan, B.K. Chen, J., Digby, J.E., Keay, S.D., Kennedy, C.R., Randeva, H.S., 2006. Increased visfatin messenger ribonucleic acid and protein levels in adipose tissue and adipocytes in women with polycystic ovary syndrome: parallel increase in plasma visfatin. J. Clin. Endocrinol. Metab. 91 (12), 5022-5028.

Tanaka, N., Sano, K., Horiuchi, A., Tanaka, E., Kiyosawa, K., Aoyama, T., 2008. Highly purified eicosapentaenoic acid treatment improves nonalcoholic steatohepatitis. J. Clin. Gastroenterol. 42 (4), 413-418.

Vargas, M.L., Almario, R.U., Buchan, W., Kim, K., Karakas, S.E., 2011. Metabolic and endocrine effects of long-chain versus essential omega-3 polyunsaturated fatty acids in polycystic ovary syndrome. Metabolism 60 (12), 1711-1718.

Wang, Q., Sun, Y., Ma, A., Li, Y., Han, X., Liang, H., 2010. Effects of vitamin E on plasma lipid status and oxidative stress in Chinese women with metabolic syndrome. Int. J. Vitam. Nutr. Res. 80 (3), 178-187.

Weerakiet, S., Tingthanatikul, Y., Sophonsritsuk, A., Choktanasiri, W. Wansumrith, S., Rojanasakul, A., 2004. Efficacy of metformin on ovulation induction in Asian women with polycystic ovary syndrome. Gynecol. Endocrinol. 19 (4), 202-207.

Youn, J.Y., Siu, K.L., Lob, H.E., Itani, H., Harrison, D.G., Cai, H., 2014. Role of vascular oxidative stress in obesity and metabolic syndrome. Diabetes 63 (7), $2344-2355$ 